ERR A T UM

Arnaud Fumal • Valentin Bohotin •

Michel Vandenheede • Laurence Seidel •

Victor De Pasqua • Alain Maertens de Noordhout •

Jean Schoenen

\title{
Effects of repetitive transcranial magnetic stimulation on visual evoked potentials: new insights in healthy subjects
}

Published online: 12 June 2003

(C) Springer-Verlag 2003

\section{Exp Brain Res (2003) 150:332-340}

In the original article, Fig. 3 was published incorrect. The correct figure is shown below.
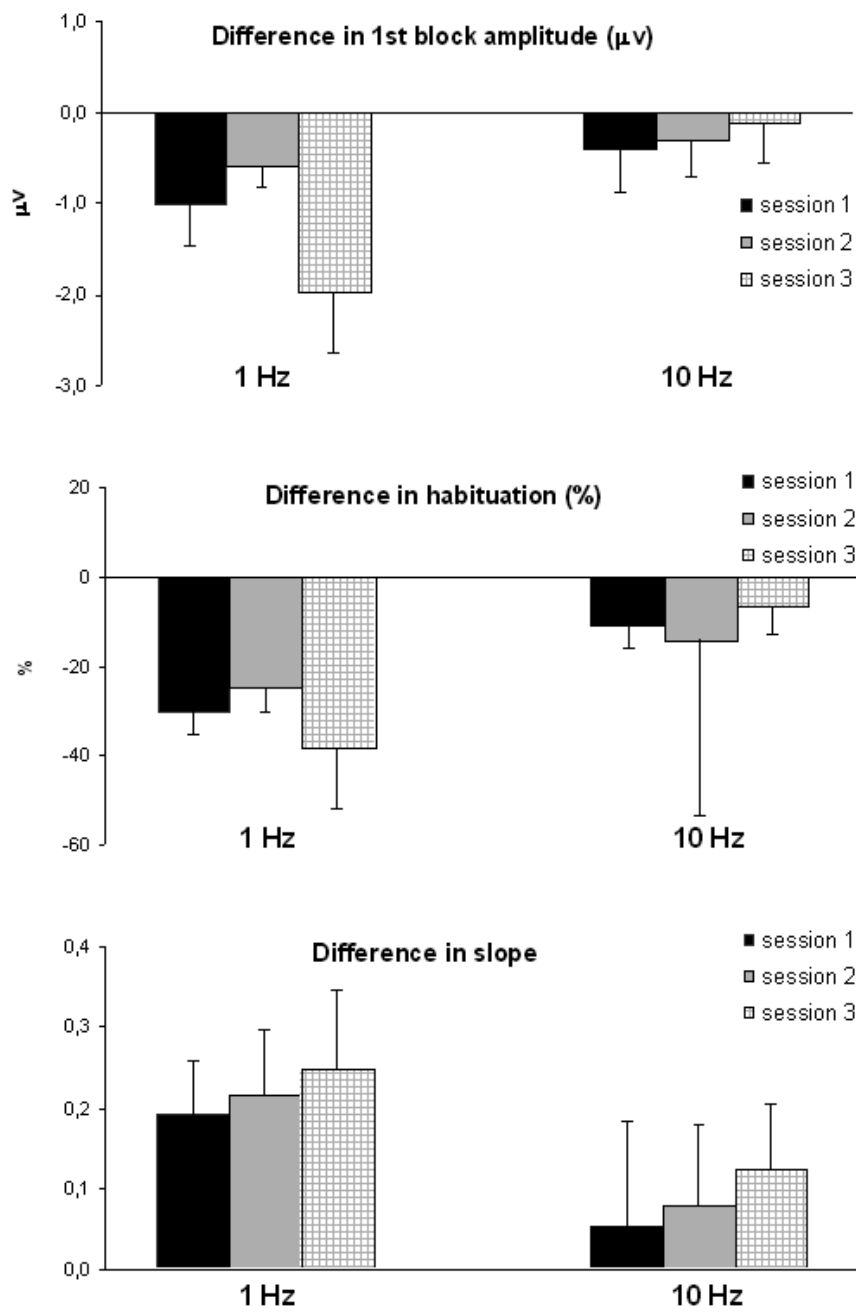

Fig. 3 Poststimulus changes in first block amplitude ( $\mu \mathrm{V}$, upper), habituation $(\%$, middle) and habituation slope (lower) of the N1-P1 component of PR-VEP in three rTMS sessions at 1 or $10 \mathrm{~Hz}$ repeated in the same ten subjects (mean $\pm \mathrm{SD}$ )
The online version of the original article can be found at http:// dx.doi.org/10.1007/s00221-003-1423-7

A. Fumal · V. Bohotin · M. Vandenheede · V. De Pasqua A. M. de Noordhout · J. Schoenen (匹)

University Department of Neurology,

CHR Citadelle Hospital,

4000 Liège, Belgium

e-mail: jschoenen@ulg.ac.be

Tel.: +32-4-2256111

Fax: +32-4-2256451

\section{A. Fumal $\cdot$ J. Schoenen}

Department of Neuroanatomy,

University of Liège,

4020 Liège, Belgium

L. Seidel

Department of Medical Informatics, CHU Hospital,

University of Liège,

4000 Liège, Belgium 